\title{
Activity of taurolidine gels on ex vivo periodontal biofilm
}

\author{
Luca Pirracchio $^{1} \cdot$ Aline Joos $^{1} \cdot$ Nina Luder ${ }^{1} \cdot$ Anton Sculean $^{1} \cdot$ Sigrun Eick $^{1}$ (I) \\ Received: 19 December 2016 / Accepted: 6 December 2017 / Published online: 14 December 2017 \\ (C) Springer-Verlag GmbH Germany, part of Springer Nature 2017
}

\begin{abstract}
Objectives The purpose of this study is to evaluate the activity of two different taurolidine (TAU) gels in comparison with a $0.2 \%$ chlorhexidine (CHX) gel on an ex vivo subgingival biofilm.

Material and methods Subgingival including supragingival biofilm samples from periodontitis patients were cultured for 10 days, before TAU 1\% and TAU 3\% gels and CHX gel were applied for $10 \mathrm{~min}$ and thereafter diluted with nutrient media to $10 \%$ for $50 \mathrm{~min}$. One third of the samples were analyzed for bacterial counts, biofilm quantity, and biofilm metabolic activity. In the two other thirds, $90 \%$ of the nutrient media were replaced and biofilms were incubated for $23 \mathrm{~h}$. The second third was analyzed in the same way as before. In the third part, patients' microorganisms were added again and incubated for additional $24 \mathrm{~h}$ to allow reformation of biofilm before proceeding to analysis.

Results Decrease of bacterial counts in biofilms was highest following application of TAU 3\% after $60 \min \left(0.87 \log _{10} \mathrm{cfu}\right.$, corresponding $86.5 \%$ ), 24 and $48 \mathrm{~h}$ (reformation of biofilms), respectively. All antimicrobials reduced biofilm quantity after $24 \mathrm{~h}$ (each $p<0.05$ ) and following reformation of biofilms (each $p<0.01$ ). Metabolic activity in biofilms was decreased at 60 min (each $p<0.05$ ) and at $24 \mathrm{~h}($ each $p<0.01)$ after application of TAU gels, while the activity of the reformed biofilm was lower after application of all evaluated antimicrobials (each $p<0.01$ ) than in the control group (e.g., without exposure to antimicrobials).

Conclusion The antimicrobial activity of taurolidine gels clearly depends on its taurolidine concentration. A high concentrated taurolidine gel is equally active or even superior to $0.2 \%$ chlorhexidine gel. However, the activity of antimicrobials is limited in a complex established biofilm and underlines the pivotal role of mechanical biofilm disruption.

Clinical relevance Within their limits, the data suggest that TAU $3 \%$ gel might represent a potential alternative to $0.2 \%$ chlorhexidine gel.
\end{abstract}

Keywords Biofilm $\cdot$ Antimicrobial $\cdot$ Periodontal therapy

\section{Introduction}

Periodontitis is an inflammatory oral disease in response to oral biofilm which affects and destroys the tooth's supporting tissues leading finally to tooth loss. The etiology of periodontitis is that microbiota in subgingival biofilm including Porphyromonas gingivalis, Aggregatibacter actinomycetemcomitans, Tannerella forsythia, and Treponema denticola induces innate,

Aline Joos and Nina Luder contributed equally to this work.

Sigrun Eick

sigrun.eick@zmk.unibe.ch

1 School of Dental Medicine, Department of Periodontology, University of Bern, Freiburgstrasse 7, CH-3010 Bern, Switzerland inflammatory, and adaptive host response [1]. Certain microorganisms, e.g., $P$. gingivalis may act as keystone pathogens by changing a symbiotic microbiota into a dysbiotic one via modifying host response [2].

The key step of periodontal therapy consists of the removal of supra- and subgingival bacterial biofilm [3]. A systematic review showed that improvement of clinical attachment level is primarily achieved by mechanical non-surgical therapy [4]; the use of antimicrobials is generally recommended for additional use [5]. In dentistry, chlorhexidine is one of the best documented antimicrobial agents [6]. Chlorhexidine is active against most microbial species [7,8], but it is also cytotoxic $[9,10]$. Moreover, discoloration and taste irritation occur frequently after application of various chlorhexidine-containing formulations [11, 12]. Substantial data indicate that the use of adjunctive systemic antibiotics appears to be beneficial in 
advanced and severe cases to arrest the bacterial biofilm caused infection and subsequent inflammation [13]. However, the long-term clinical benefit following the use of antibiotics is still unclear and needs to be carefully considered, especially in the light of the global increase of antibiotic resistance $[14,15]$. Therefore, the use of systemic antibiotics in the treatment of periodontal infections should be carefully considered and obviously, there is a clear need for alternative antimicrobial agents.

Taurolidine is most discussed as a lock solution for central venous catheters because of its antibacterial and anti-biofilm properties [16]. Antimicrobial activity was described against gram-positive and gram-negative bacteria as well as against Candida spp. [17]. It exerts its activity by inactivating endotoxin in gram-negative bacteria [18] and interacting with peptidoglycan [19].

Taurolidine appears to be a potential alternative also in dentistry. Several years ago, a potential antimicrobial activity of taurolidine was reported against oral microorganisms [20, 21]. Recently, our group has shown that $2 \%$ taurolidine is effective in killing supragingival plaque [22]. In earlier studies, the MICs of taurolidine against oral species were determined as all below $5 \%$ of the normally used concentration of that substance with the exception of Candida albicans [23]. Moreover, previous data from a series of studies performed in our laboratory have shown that taurolidine solutions and taurolidine gels inhibited clearly the formation of defined biofilms containing laboratory strains [24, 25].

Therefore, the aim of the present study was to determine the activity of two different taurolidine gels as compared with a $0.2 \%$ chlorhexidine gel on an ex vivo subgingival biofilm formed for 10 days and on its reformation including the assessment of the killing of bacteria within the biofilm, of the biofilm quantity, and of the biofilm metabolic activity.

\section{Material and methods}

\section{Sampling from chronic periodontitis patients}

The Ethical Committee of the Canton Bern approved the study protocol (KEK 035/2015). After signing the informed consent form, biofilm samples were obtained from nine patients with advanced chronic periodontitis referred to the Department of Periodontology, University of Bern, School of Dental Medicine.

For inclusion in the study, the following criteria had to be fulfilled: probing depths (PD) of $\geq 5 \mathrm{~mm}$ at least at four nonadjacent sites and presence of at least two of the main four bacterial species associated with periodontal disease: A. actinomycetemcomitans, P. gingivalis, T. denticola, and T. forsythia detected via routinely used microIdent ${ }^{\circledR}$ test (Hain Lifescience, Nehren, Germany). Exclusion criteria were as follows: intake of antibiotics 3 months prior to the study, periodontal therapy within the last 6 months, and diabetes or other severe systemic disorders affecting the immune system.

Patients were asked to refrain from oral hygiene for $24 \mathrm{~h}$ in the areas where plaque was to be sampled. The deepest pockets per quadrant were selected. Without removing supragingival plaque, each two paper points (ISO 055) were inserted until resistance was felt. After $30 \mathrm{~s}$, the paper points were removed, transferred into tubes containing $1 \mathrm{ml}$ of transport media (reduced transport fluid (RTF)) [26], and proceeded immediately to the laboratory where they were kept at $4{ }^{\circ} \mathrm{C}$.

In addition, about $2 \mathrm{ml}$ of non-stimulated saliva were collected from each individual and centrifuged at $500 \mathrm{~g}$ for $10 \mathrm{~min}$.

\section{Antimicrobials}

The antimicrobials to be tested were taurolidine in $1 \%(w / w)$ (TAU $1 \%)$ and 3\% (w/w) (TAU 3\%) gel formulation (1\% PerioSept Gel, 3\% PerioSept Gel, both Geistlich Pharma AG, Wolhusen, Switzerland).

A $0.2 \%(w / w)$ chlorhexidine gel (CHX 0.2\%) (Plak-Out Gel (Kerr-Hawe SA, Bloggio, Switzerland) as a positive control and $\mathrm{dH}_{2} \mathrm{O}$ as a negative control were included in addition.

\section{Ex vivo biofilm model}

The ex vivo model was modified to that described by Walker and Sedlacek [27].

Biofilms were cultured for each of the nine included patients separately. The day before starting biofilm formation, wells of 96-well plates had been prepared by coating with poly-L-lysine (1:10 diluted with $\left.\mathrm{dH}_{2} \mathrm{O}\right)$ overnight. After removing the non-attached poly-L-lysine solution, supernatants of the patient's own saliva mixed 1:1 with phosphate-buffered saline (PBS) containing 50\% of inactivated human serum (Sigma-Aldrich Chemie GmbH, Buchs, Switzerland) (10 $\mu \mathrm{l}$ per well) were added and exposed to UV for $30 \mathrm{~min}$ and left in place. Meanwhile, bacteria were suspended in RTF by vortexing and ultrasonication. An amount of $0.5 \mathrm{ml}$ of RTF with bacteria was mixed with $19.5 \mathrm{ml}$ of nutrient broth (Wilkins Chalgren broth (Oxoid, Basingstoke, GB) containing $5 \mu \mathrm{g} / \mathrm{ml} \mathrm{NAD}$ and $5 \mu \mathrm{g} / \mathrm{ml}$ thiamine pyrophosphate (SigmaAldrich Chemie $\mathrm{GmbH}$ )). Thereafter, $150 \mu$ l of the suspension was added to each well. Biofilms were incubated for 10 days in an anaerobic atmosphere $\left(85 \% \mathrm{~N}_{2}, 10 \% \mathrm{H}_{2}, 5 \% \mathrm{CO}_{2}\right.$ in an anaerobic workstation (DG250, Don Whitley Scientific Ltd., Shipley, UK)). Nutrient broth was exchanged every second day.

After careful removing the nutrient media, $20 \mu \mathrm{l}$ of the undiluted test substances (1\% taurolidine, 3\% taurolidine, $0.2 \%$ chlorhexidine) were given to biofilms. After $10 \mathrm{~min}$, 
nutrient broth was added in a ratio of 1:9 leading to a concentration of $10 \%$ of the substance $(0.1 \%$ taurolidine, $0.3 \%$ taurolidine, $0.02 \%$ chlorhexidine) in the media. After 60 min, media was removed and the biofilms were carefully rinsed in one third of the wells. Here, counts of bacteria, metabolic activity of biofilm, and biofilm quantity (amount of matrix) were determined thereafter.

In the two other thirds of the wells, $90 \%$ of the nutrient media were exchanged by fresh ones (concentration of $1 \%$ of the substance in the medium: $0.01 \%$ taurolidine, $0.03 \%$ taurolidine, $0.002 \%$ chlorhexidine). After an additional incubation of $23 \mathrm{~h}$, procedure was as after $60 \mathrm{~min}$ in the second third.

From the last third of wells, the nutrient media was removed. After careful washing, $0.5 \mathrm{ml}$ of RTF with bacteria (which were kept at $-80{ }^{\circ} \mathrm{C}$ ) mixed with $19.5 \mathrm{ml}$ of nutrient broth were added for an additional incubation of $24 \mathrm{~h}$ to assess the antimicrobials' influence on reformation of biofilm (recolonization). Thereafter at $48 \mathrm{~h}$, samples were analyzed as for the time of point $24 \mathrm{~h}$.

\section{Analyses of biofilms}

Bacterial counts were determined by enumeration of total colony forming units (cfu) after scraping the biofilm from the surface, extensive mixing, making a serial dilution, and plating $25 \mu \mathrm{l}$ each on tryptic soy agar plates with $5 \%$ of sheep blood and anaerobic cultivation for 10 days. In addition, 16S rDNA analysis (real-time PCR) was made for the presence of major species being associated with periodontitis ( $P$. gingivalis, T. forsythia, T. denticola, and A. actinomycetemcomitans) by using GoTaq qPCR Master Mix (Promega Corporation, Madison, WI, USA), as described recently [28].

Quantification of the biofilms was made according to recently published protocols [29]. After rinsing, the biofilms were fixed at $60{ }^{\circ} \mathrm{C}$ for $60 \mathrm{~min}$. Thereafter, biofilms were stained with $50 \mu \mathrm{l}$ per well $0.06 \%(w / v)$ crystal violet (Sigma-Aldrich Chemie $\mathrm{GmbH}$ ) for $10 \mathrm{~min}$ and the staining was quantified by using a plate reader (ELx808, Biotek Instruments, Winooski, VT, USA) at $600 \mathrm{~nm}$.

Biofilm metabolic activity was assessed with using Alamar blue as a redox indicator [30]. Five microliters of Alamar blue (alamarBlue ${ }^{\circledR}$ reagent, Thermo Fisher Scientific Inc., Waltham, MA, USA) was mixed with $100 \mu$ of the nutrient media and added to the biofilm. After extensive mixing with the biofilm and an incubation for $1 \mathrm{~h}$ at $37^{\circ} \mathrm{C}$, absorbances were measured at 570 against $600 \mathrm{~nm}$ by using a microplate reader (ELx808, Biotek).

\section{Statistical methods}

Biofilm samples per patient were always assayed in independent duplicates, meaning in a total of 18 samples were analyzed per group, time, and method each. ANOVA with post hoc LSD was used for statistical analysis. The level of significance was set to $p=0.05$. Software SPSS 22.0 (IBM SPSS Statistics, Chicago, IL, USA) was used.

\section{Results}

\section{Microbial counts}

The cfu counts in biofilms without exposure to antimicrobials were $7.68 \pm 0.19 \log _{10}$ cfu after 10 days $(60 \mathrm{~min}), 7.88 \pm 0.25$ $\log _{10}$ cfu after 11 days $(24 \mathrm{~h}$ ), and $8.60 \pm 0.61$ after 12 days (48 h, $24 \mathrm{~h}$ of reformation of biofilm; $p<0.001$ vs. $60 \mathrm{~min}, 24 \mathrm{~h}$ ). Sixty minutes after exposing the biofilms to any of the antimicrobials, the counts in biofilms were significantly reduced (TAU 1\%: reduction $0.36 \log 10 \mathrm{cfu}, p=0.021$; TAU $3 \%$ : reduction $0.87 \log _{10} \mathrm{cfu}, p<0.001$ and CHX $0.2 \%$ : reduction $0.64 \log 10 \mathrm{cfu}, p<0.001)$; however, the difference was at the highest $0.87 \log _{10}$ cfu (TAU 3\%) (corresponding to $86.5 \%$ reduction). TAU $3 \%$ was significantly more active than TAU $1 \%(p=0.001)$. After 24-h exposure, differences to control were still significant for TAU $3 \%\left(-0.58 \log _{10}, p<0.001\right)$ and for CHX $0.2 \%\left(-0.47 \log _{10}, \mathrm{p}=0.001\right)$. Only TAU $3 \%$ was able to inhibit significantly reformation of biofilms (difference $-0.61 \log _{10}, p=0.004$ ) (Fig. 1).

Samples being initially tested positively for the analyzed species were included in the nucleic acid-based analysis of single species. P. gingivalis was detected in seven, A. actinomycetemcomitans in three, and T. denticola in two of the nine patients. All biofilm control samples had been positively tested for $T$. forsythia. Counts of $P$. gingivalis and T. denticola were reduced after $60 \mathrm{~min}$ exposure to TAU $3 \%$ $(p=0.036, p=0.022)$ and CHX 0.2\% $(p=0.020, p=0.023)$. In reformed biofilm, the counts were less for $T$. forsythia after

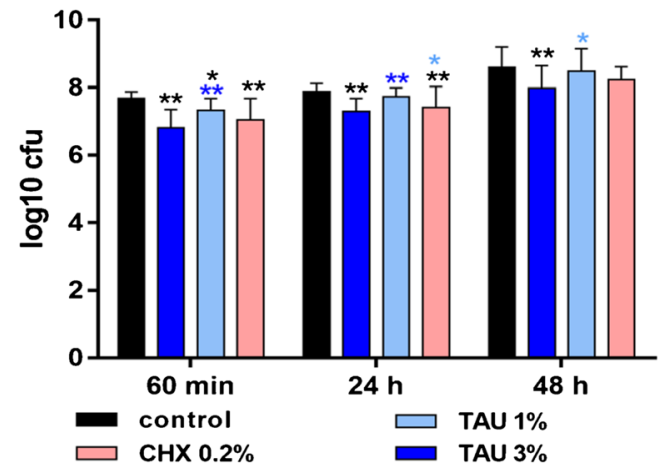

Fig. 1 Total counts of colony forming units (cfu, mean \pm SD) in biofilm $60 \mathrm{~min}$ and $24 \mathrm{~h}$ as well as after $48 \mathrm{~h}$ (allowing reformation of biofilm for $24 \mathrm{~h}$ ) after exposing biofilms to undiluted 1 and $3 \%$ taurolidine gels (TAU $1 \%$, TAU $3 \%$ ), $0.2 \%$ chlorhexidine gel (CHX $0.2 \%$ ) for $10 \mathrm{~min}$, a following dilution to $10 \%$ of the gels $(0.1 \%$ taurolidine, $0.3 \%$ taurolidine, $0.02 \%$ chlorhexidine) for $50 \mathrm{~min}$ (and to $1 \%$ for $23 \mathrm{~h}$ ). $* p<0.05 ; * * p<0.01$ compared to control. **p< $<.01$ compared to TAU $3 \%$. $* p<0.05$ compared to TAU $1 \%$ 
TAU 3\% $(p=0.017)$ and for all analyzed species after CHX $0.2 \%$ ( $P$. gingivalis $p=0.022, T$. forsythia $p=0.039$, T. denticola $p=0.003$, A. actinomycetemcomitans $p=0.012$ ) than in the controls (Fig. 2).

\section{Biofilm quantity and metabolic activity}

All treatments significantly reduced biofilm quantity after $24 \mathrm{~h}$ (TAU 3\% $p=0.023$, TAU $1 \% p=0.028$, CHX $0.2 \%$ $p=0.012$ ) and after $48 \mathrm{~h}$ (reformation of biofilms for $24 \mathrm{~h}$ ) (each $p<0.001$ ). There was no difference between the antimicrobials (Fig. 3).

Metabolic activity in biofilms was significantly reduced 60 min after TAU $3 \%(p=0.016)$ and TAU $1 \%(p=0.026)$ and $24 \mathrm{~h}$ after TAU $3 \%(p=0.002)$ and TAU $1 \%(p=0.004)$. The metabolic activity of the reformed biofilm was always lower after any antimicrobials application than in the control without exposure to antimicrobials (TAU 3\% and TAU 1\%: $p<0.001$, CHX 0.2\%: $p=0.001$; Fig. 4).

\section{Discussion}

The purpose of the present in vitro study was to evaluate the activity of taurolidine gels on an ex vivo biofilm generated from periodontitis patients' samples.

Samples including primarily subgingival but also supragingival biofilm were obtained from periodontitis patients that harbored bacteria associated with periodontal disease. Sampling method was in accordance with those used for routine microbiological analysis. It is based on a report that without removing supragingival biofilm, the detection rate of

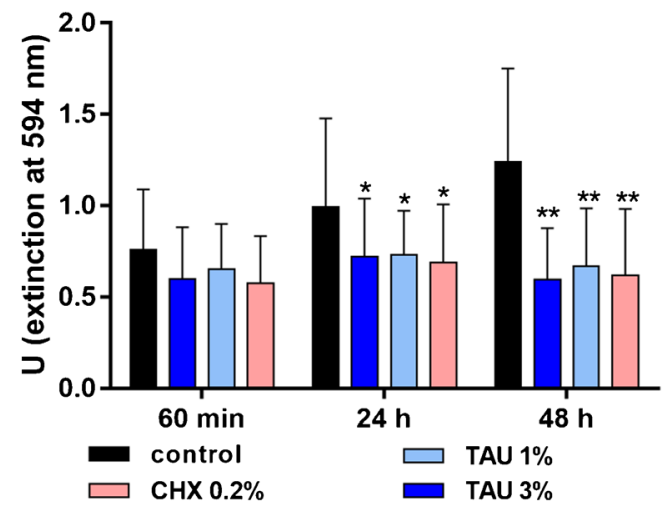

Fig. 3 Biofilm quantity expressed in extinction units (mean \pm SD) at $600 \mathrm{~nm}$ after crystal violet staining in biofilm $60 \mathrm{~min}$ and $24 \mathrm{~h}$ as well as after $48 \mathrm{~h}$ (allowing reformation of biofilm for $24 \mathrm{~h}$ ) after exposing biofilms to undiluted 1 and $3 \%$ taurolidine gels (TAU 1\%, TAU 3\%), $0.2 \%$ chlorhexidine gel (CHX $0.2 \%$ ) for $10 \mathrm{~min}$, a following dilution to $10 \%$ of the gels $(0.1 \%$ taurolidine, $0.3 \%$ taurolidine, $0.02 \%$ chlorhexidine) for $50 \mathrm{~min}$ (and to $1 \%$ for $23 \mathrm{~h}$ ). * $p<0.05$; * $p<0.01$ compared to control

bacterial species being associated with periodontitis is higher [31]. Subsequently, the plaque samples were used to form an ex vivo biofilm. The modifications of the model described by Walker and Sedlacek [27] include the use of native saliva without any sterile filtration and the repeated addition of subgingival plaque samples to mimic reformation. The rationale for using native saliva is to ensure its unchanged protein composition, since it has been shown that filtering decreases the protein content and modifies the protein composition [32]. The results revealed consistently higher bacterial counts and higher biofilm quantity and metabolic activity in the reformed than in the first formed biofilm, thus confirming successful incorporation of these microorganisms in the biofilms.
Fig. 2 Counts of selected bacterial species $($ mean $\pm \mathrm{SD})$ in biofilm $60 \mathrm{~min}$ and $24 \mathrm{~h}$ as well as after $48 \mathrm{~h}$ (allowing reformation of biofilm for $24 \mathrm{~h}$ ) after exposing biofilms to undiluted 1 and $3 \%$ taurolidine gels (TAU $1 \%$, TAU $3 \%), 0.2 \%$ chlorhexidine gel (CHX $0.2 \%$ ) for $10 \mathrm{~min}$, a following dilution to $10 \%$ of the gels $(0.1 \%$ taurolidine, $0.3 \%$ taurolidine, $0.02 \%$ chlorhexidine) for $50 \mathrm{~min}$ (and to $1 \%$ for $23 \mathrm{~h}$ ). $* p<0.05 ; * * p<0.01$ compared to control. * $p<0.05 ; * * p<0.01$ compared to TAU $1 \%$
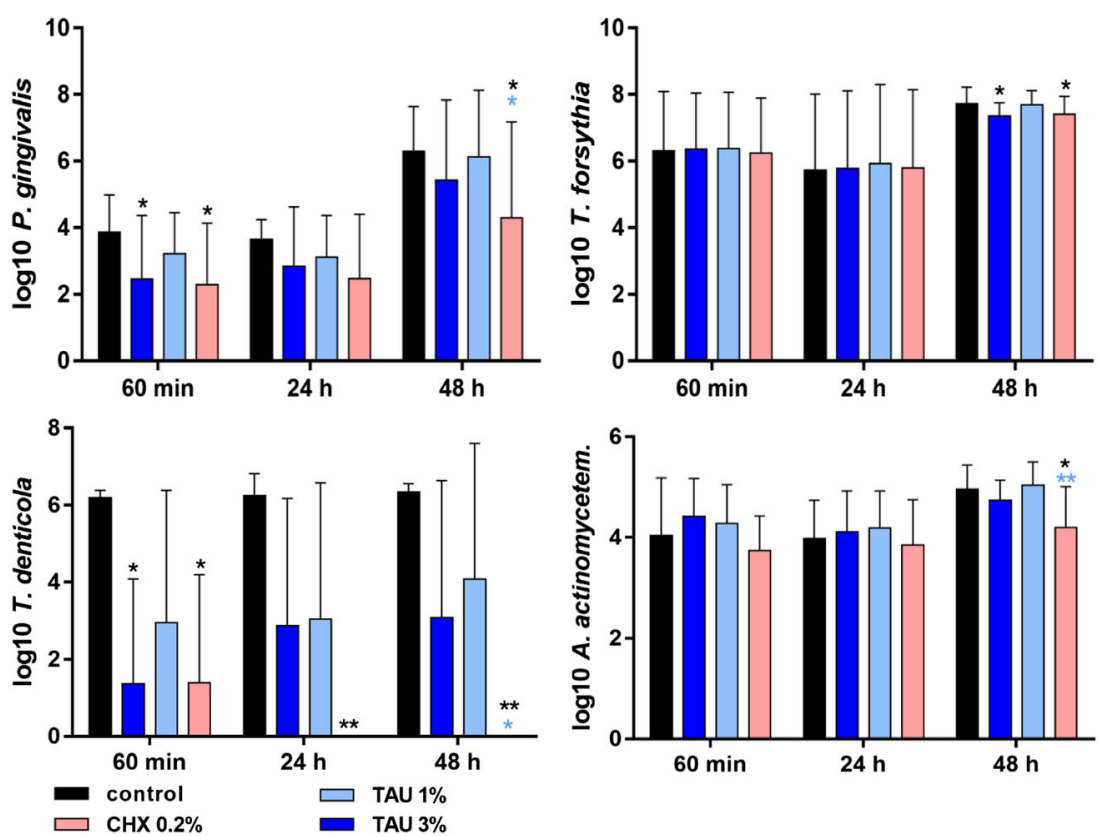


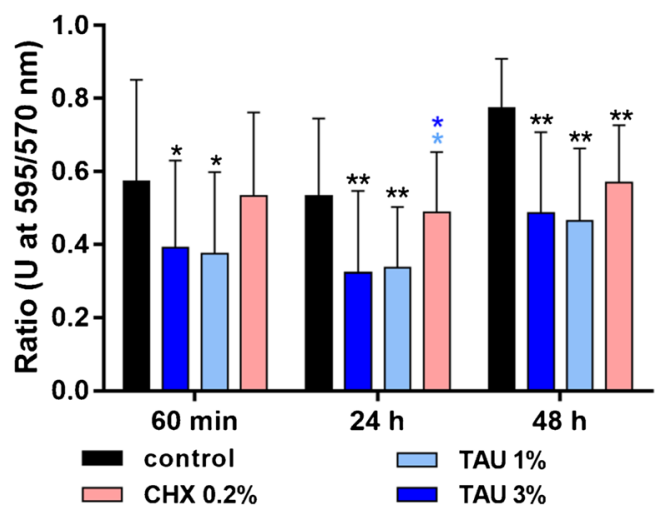

Fig. 4 Biofilm metabolic activity expressed as extinction units (mean \pm SD) at 570/600 nm in biofilm $60 \mathrm{~min}$ and $24 \mathrm{~h}$ as well as after $48 \mathrm{~h}$ (allowing reformation of biofilm for $24 \mathrm{~h}$ ) after exposing biofilms to undiluted 1 and $3 \%$ taurolidine gels (TAU 1\%, TAU 3\%), $0.2 \%$ chlorhexidine gel (CHX $0.2 \%$ ) for $10 \mathrm{~min}$, a following dilution to $10 \%$ of the gels $(0.1 \%$ taurolidine, $0.3 \%$ taurolidine, $0.02 \%$ chlorhexidine) for $50 \mathrm{~min}$ (and to $1 \%$ for $23 \mathrm{~h}$ ). $* p<0.05 ; * * p<0.01$ compared to control. $* p<0.05$ compared to TAU $3 \%$. $* p<0.05$ compared to TAU $1 \%$

In the present study, a complex biofilm was formed and treated with antimicrobials. Subsequent analyses were performed by several methods. Ex vivo oral biofilms were occasionally used for determining activity of antimicrobials. Fourhour-10-day-old biofilms had been exposed to antibiotics for $48 \mathrm{~h}$ [33]. The activity of chlorhexidine was compared with photodynamic therapy on biofilms cultured for 24 and $72 \mathrm{~h}$ [34]. Oral antiseptics (e.g., mouth rinses) were tested to inhibit salivary biofilm formation [35]. Sometimes, plaque samples are harvested and directly exposed to potential antimicrobials in the laboratory $[36,37]$.

Teeth are surrounded by a continuous flow of gingival crevicular fluid [38]. In order to simulate the in vivo situation, the applied antimicrobial was diluted to $10 \%$ after $10 \mathrm{~min}$ and in part additionally after $60 \mathrm{~min}$ to $1 \%$. The highest reduction of bacterial counts after the application of antimicrobials was $86.5 \%$. However, a killing activity of an antimicrobial is generally defined as a reduction by at least $3 \log _{10}$ over a defined time; here, only $0.87 \log _{10}$ were reached. In our previously performed study using a defined 12-species biofilm, the same antimicrobial (TAU 3\%) reached $3.63 \log _{10}$, [25]. Three percent taurolidine has been in contact with the biofilm for $60 \mathrm{~min}$ before diluting to $0.3 \%$; in the present study, dilution was already after $10 \mathrm{~min}$ to $0.3 \%$.

Comparing TAU 3\% with TAU 1\%, a clear concentration dependent activity was visible on total bacterial counts (cfu) as well as on selected species ( $P$. gingivalis and $T$. denticola after $60 \mathrm{~min}$ ) in biofilm. This is in agreement with findings from previous studies using a 12-species biofilm, where higher concentrations of taurolidine solutions [24] and taurolidine gels [25] were more bactericidal than lower ones. However, in the present study, there was no difference between the two taurolidine gels regarding biofilm quantity and metabolic activity. Both gels decrease biofilm metabolic activity already after $60 \mathrm{~min}$, thus suggesting that a lower concentration of taurolidine may already inhibit bacterial metabolism. Biofilm quantity determined by crystal violet staining is reduced after $24 \mathrm{~h}$. Biofilms are not only bacteria, they consist of self-produced matrix of extracellular polymeric substances [39]. Interference with bacterial matrix components is an approach in the development of anti-biofilm drugs [40]; investigating this aspect in more detail might be of interest in further research. An activity of the vehicle used in taurolidine gels on biofilm metabolic activity and biofilm quantity cannot be ruled out. In our previous study [25], no influence of the vehicle on bacterial counts was seen. Due to the complexity of the study design, a vehicle could not be included.

In the present study, TAU 3\% reduced as CHX $0.2 \%$ total bacterial counts (cfu) in biofilm after $60 \mathrm{~min}$ and $24 \mathrm{~h}$. TAU $3 \%$ was the only tested compound showing a very small but statistically significantly different reduction of total bacterial counts (cfu) in the reformed biofilm. These findings are of particular interest, especially in comparison with chlorhexidine, a compound with known high substantivity [41].

Taken together, the available data indicate that taurolidine is a potential alternative as an antimicrobial. It interacts with bacterial cell wall components [19] while in long-term users, no decreased susceptibility of bacteria causing bloodstream infections was observed [42]. Beside its antimicrobial activity, taurolidine inhibits the expression of pro-inflammatory cytokines [43]. In an animal model, there was no toxicity found [44]; in in vitro assays, cytotoxicity was comparable to other agents like 3\% hydrogen peroxide [45] or chlorhexidine [46].

However, the number of studies investigating the antibacterial properties of taurolidine on oral biofilms is still low. Besides the few studies focusing on supra- and subgingival biofilm $[22,24,25]$, it was found that in contrast to chlorhexidine, the antimicrobial activity of taurolidine is not affected in a serum-rich environment [23]. Furthermore, a recent in vitro study showed that taurolidine might enhance effectiveness of plaque-removing procedures on titanium surfaces with plastic curettes and glycine powder airflow [47]. Interestingly, in simulated endodontic infections, taurolidine was more bactericidal than chlorhexidine but less than calcium hydroxide against Enterococcus faecalis biofilm [46].

All these findings appear to suggest that taurolidine may be a potentially relevant antimicrobial agent for an adjunctive use to scaling and root planning in the treatment of periodontal pockets. Since none of the currently available instrumentation techniques can completely remove the supra- and subgingival biofilm [48], the use of adjunctive antimicrobial substances may be of potential benefit [49]. Nevertheless, it should be kept in mind that in the present in vitro study, the reduction of bacterial counts in biofilm never exceeded one $\log _{10}$ which in turn, underlines once more the fact that antimicrobials alone are not able to completely destroy an already established 
complex biofilm. Therefore, the use of antimicrobials can only be recommended in conjunction with mechanical biofilm disruption suggesting once more that mechanical biofilm removal is still the gold standard in the therapy of periodontitis [50].

In summary, the present study has shown that: (i) an ex vivo biofilm model that closely resembles the in vivo situation and enables the evaluation of various antimicrobials can be predictably established; (ii) the activity of antimicrobials is limited in a complex established biofilm; (iii) the antimicrobial activity of taurolidine gels clearly depends on its active compound concentration; and (iv) 3\% taurolidine gel appears to be an interesting alternative to chlorhexidine as an adjunct in periodontal therapy and warrants further evaluation in clinical settings.

Acknowledgements The authors are grateful to Anna Magdon (University of Bern, Department of Periodontology, Laboratory of Oral Microbiology) for the technical assistance.

Funding The study was funded by Geistlich Pharma AG, Wolhusen, Switzerland.

\section{Compliance with ethical standards}

Conflict of interest The authors declare that they have no conflict of interest.

Ethical approval All procedures performed in studies involving human participants were in accordance with the ethical standards of the institutional and/or national research committee and with the 1964 Helsinki declaration and its later amendments or comparable ethical standards.

Informed consent Informed consent was obtained from all individual participants included in the study.

\section{References}

1. Silva N, Abusleme L, Bravo D, Dutzan N, Garcia-Sesnich J, Vernal R, Hernandez M, Gamonal J (2015) Host response mechanisms in periodontal diseases. J Appl Oral Sci 23(3): 329-355. https://doi.org/10.1590/1678-775720140259

2. Hajishengallis G (2014) Immunomicrobial pathogenesis of periodontitis: keystones, pathobionts, and host response. Trends Immunol 35(1):3-11. https://doi.org/10.1016/j.it.2013.09. 001S1471-4906(13)00145-2

3. Lang NP (2015) Group B. Reactor report. Non-surgical periodontal therapy: mechanical debridement, antimicrobial agents and other modalities. J Int Acad Periodontol 17(1 Suppl):31-33

4. Herrera $\mathrm{D}$ (2016) Scaling and root planning is recommended in the nonsurgical treatment of chronic periodontitis. J Evid Based Dent Pract 16(1):56-58. https://doi.org/10.1016/j.jebdp.2016.01.005

5. Leszczynska A, Buczko P, Buczko W, Pietruska M (2011) Periodontal pharmacotherapy - an updated review. Adv Med Sci 56(2):123-131. https://doi.org/10.2478/v10039-011-0044-9

6. Baehni PC, Takeuchi Y (2003) Anti-plaque agents in the prevention of biofilm-associated oral diseases. Oral Dis 9(Suppl 1):23-29. https://doi.org/10.1034/j.1601-0825.9.s1.5.x
7. Cosyn J, Sabzevar MM (2007) Subgingival chlorhexidine varnish administration as an adjunct to same-day full-mouth root planing. II. Microbiological observations. J Periodontol 78(3):438-445. https://doi.org/10.1902/jop.2007.060222

8. De Soete M, Mongardini C, Peuwels M, Haffajee A, Socransky S, van Steenberghe D, Quirynen M (2001) One-stage fullmouth disinfection. Long-term microbiological results analyzed by checkerboard DNA-DNA hybridization. J Periodontol 72(3):374-382. https://doi.org/10.1902/jop.2001. 72.3 .374

9. Hidalgo E, Dominguez C (2001) Mechanisms underlying chlorhexidine-induced cytotoxicity. Toxicol in Vitro 15(4-5):271276. https://doi.org/10.1016/S0887-2333(01)00020-0

10. Eick S, Goltz S, Nietzsche S, Jentsch H, Pfister W (2011) Efficacy of chlorhexidine digluconate-containing formulations and other mouthrinses against periodontopathogenic microorganisms. Quintessence Int 42(8):687-700

11. Lorenz K, Bruhn G, Heumann C, Netuschil L, Brecx M, Hoffmann $\mathrm{T}$ (2006) Effect of two new chlorhexidine mouthrinses on the development of dental plaque, gingivitis, and discolouration. A randomized, investigator-blind, placebo-controlled, 3-week experimental gingivitis study. J Clin Periodontol 33(8):561-567. https://doi.org/10.1111/j.1600-051X.2006.00946.x

12. Laugisch O, Ramseier CA, Salvi GE, Hagi TT, Burgin W, Eick S, Sculean A (2016) Effects of two different post-surgical protocols including either $0.05 \%$ chlorhexidine herbal extract or $0.1 \%$ chlorhexidine on post-surgical plaque control, early wound healing and patient acceptance following standard periodontal surgery and implant placement. Clin Oral Investig. https://doi.org/10.1007/ s00784-016-1713-7

13. Zandbergen D, Slot DE, Niederman R, Van der Weijden FA (2016) The concomitant administration of systemic amoxicillin and metronidazole compared to scaling and root planing alone in treating periodontitis: a systematic review. BMC Oral Health 16(1):27. https://doi.org/10.1186/s12903-015-0123-6

14. Harks I, Koch R, Eickholz P, Hoffmann T, Kim TS, Kocher T, Meyle J, Kaner D, Schlagenhauf U, Doering S, Holtfreter B, Gravemeier M, Harmsen D, Ehmke B (2015) Is progression of periodontitis relevantly influenced by systemic antibiotics? A clinical randomized trial. J Clin Periodontol 42(9):832-842. https://doi.org/10.1111/jcpe.12441

15. Oberoi SS, Dhingra C, Sharma G, Sardana D (2015) Antibiotics in dental practice: how justified are we. Int Dent J 65(1):4-10. https://doi.org/10.1111/idj.12146

16. Pittiruti M, Bertoglio S, Scoppettuolo G, Biffi R, Lamperti M, Dal Molin A, Panocchia N, Petrosillo N, Venditti M, Rigo C and DeLutio E (2016) Evidence-based criteria for the choice and the clinical use of the most appropriate lock solutions for central venous catheters (excluding dialysis catheters): a GAVeCeLT consensus. J Vasc Access 0(6): 453-464. doi:https://doi.org/10.5301/jva.5000576

17. Sherertz RJ, Boger MS, Collins CA, Mason L, Raad II (2006) Comparative in vitro efficacies of various catheter lock solutions. Antimicrob Agents Chemother 50(5):1865-1868. https://doi.org/ 10.1128/AAC.50.5.1865-1868.2006

18. Gidley MJ, Sanders JK, Myers ER, Allwood MC (1981) The mode of antibacterial action of some 'masked' formaldehyde compounds. FEBS Lett 127(2):225-227

19. Caruso F, Darnowski JW, Opazo C, Goldberg A, Kishore N, Agoston ES, Rossi M (2010) Taurolidine antiadhesive properties on interaction with E. coli; its transformation in biological environment and interaction with bacteria cell wall. PLoS One 5(1):e8927. https://doi.org/10.1371/journal.pone.0008927

20. Reynolds S, Moran J, Wade WG, Addy M, Newcombe R (1991) Taurolin as an oral rinse. II. Effects on in vitro and in vivo plaque regrowth. Clin Prev Dent 13(2):18-22 
21. Reynolds S, Moran J, Addy M, Wade WG, Newcombe R (1991) Taurolin as an oral rinse. I. Antimicrobial effects in vitro and in vivo. Clin Prev Dent 13(2):13-17

22. Arweiler NB, Auschill TM, Sculean A (2012) Antibacterial effect of taurolidine (2\%) on established dental plaque biofilm. Clin Oral Investig 16(2):499-504. https://doi.org/10.1007/ s00784-011-0526-y

23. Eick S, Radakovic S, Pfister W, Nietzsche S, Sculean A (2012) Efficacy of taurolidine against periodontopathic species-an in vitro study. Clin Oral Investig 16(3):735-744. https://doi.org/ 10.1007/s00784-011-0567-2

24. Zollinger L, Schnyder S, Nietzsche S, Sculean A, Eick S (2015) Invitro activity of taurolidine on single species and a multispecies population associated with periodontitis. Anaerobe 32:18-23. https://doi.org/10.1016/j.anaerobe.2014.11.008

25. Eick S, Gloor N, Puls C, Zumbrunn J, Sculean A (2016) In vitro activity of taurolidine gel on bacteria associated with periodontitis. Clin Oral Investig 20(3):597-606. https://doi.org/10.1007/s00784015-1549-6

26. Syed SA, Loesche WJ (1972) Survival of human dental plaque flora in various transport media. Appl Microbiol 24(4):638-644

27. Walker C, Sedlacek MJ (2007) An in vitro biofilm model of subgingival plaque. Oral Microbiol Immunol 22(3):152-161. https://doi.org/10.1111/j.1399-302X.2007.00336.x

28. Eick S, Straube A, Guentsch A, Pfister W, Jentsch H (2011) Comparison of real-time polymerase chain reaction and DNA-strip technology in microbiological evaluation of periodontitis treatment. Diagn Microbiol Infect Dis 69(1):12-20. https://doi.org/10.1016/j.diagmicrobio.2010.08.017

29. Kwasny SM, Opperman TJ (2010) Static biofilm cultures of Grampositive pathogens grown in a microtiter format used for antibiofilm drug discovery. Curr Protoc Pharmacol Chapter 13:Unit 13A 8. doi:https://doi.org/10.1002/0471141755.ph13a08s50

30. Pettit RK, Weber CA, Kean MJ, Hoffmann H, Pettit GR, Tan R, Franks KS, Horton ML (2005) Microplate Alamar blue assay for Staphylococcus epidermidis biofilm susceptibility testing. Antimicrob Agents Chemother 49:2612-2617. https://doi.org/10. 1128/AAC.49.7.2612-2617.2005

31. Beikler T, Schnitzer S, Abdeen G, Ehmke B, Eisenacher M, Flemmig TF (2006) Sampling strategy for intraoral detection of periodontal pathogens before and following periodontal therapy. J Periodontol 77(8):1323-1332. https://doi.org/10. 1902/jop.2006.050204

32. Ruhl S, Berlenbach P, Langenfelder S, Horl D, Lehn N, Hiller KA, Schmalz G, Durchschlag H (2011) Integrity of proteins in human saliva after sterilization by gamma irradiation. Appl Environ Microbiol 77(3):749-755. https://doi.org/10.1128/AEM.01374-10

33. Sedlacek MJ, Walker C (2007) Antibiotic resistance in an in vitro subgingival biofilm model. Oral Microbiol Immunol 22(5):333339. https://doi.org/10.1111/j.1399-302X.2007.00366.x

34. Voos AC, Kranz S, Tonndorf-Martini S, Voelpel A, Sigusch H, Staudte H, Albrecht V, Sigusch BW (2014) Photodynamic antimicrobial effect of safranine $\mathrm{O}$ on an ex vivo periodontal biofilm. Lasers Surg Med 46(3):235-243. https://doi.org/10. 1002/lsm.22217

35. Latimer J, Munday JL, Buzza KM, Forbes S, Sreenivasan PK, McBain AJ (2015) Antibacterial and anti-biofilm activity of mouthrinses containing cetylpyridinium chloride and sodium fluoride. BMC Microbiol 15(1):169. https://doi.org/ 10.1186/s12866-015-0501-x
36. Sculean A, Auschill TM, Donos N, Brecx M, Arweiler NB (2001) Effect of an enamel matrix protein derivative (Emdogain) on ex vivo dental plaque vitality. J Clin Periodontol 28(11):1074 1078. https://doi.org/10.1034/j.1600-051X.2001.281113.x

37. Sreenivasan PK, Haraszthy VI, Zambon JJ (2013) Antimicrobial efficacy of $0.05 \%$ cetylpyridinium chloride mouthrinses. Lett Appl Microbiol 56(1):14-20. https://doi.org/10.1111/lam.12008

38. Goodson JM (2003) Gingival crevice fluid flow. Periodontol 31(1): 43-54. https://doi.org/10.1034/j.1600-0757.2003.03104.x

39. Flemming HC, Wingender J, Szewzyk U, Steinberg P, Rice SA, Kjelleberg S (2016) Biofilms: an emergent form of bacterial life. Nat Rev Microbiol 14(9):563-575. https://doi.org/10.1038/ nrmicro.2016.94

40. Ribeiro SM, Felicio MR, Boas EV, Goncalves S, Costa FF, Samy RP, Santos NC, Franco OL (2016) New frontiers for anti-biofilm drug development. Pharmacol Ther 160:133-144. https://doi.org/ 10.1016/j.pharmthera.2016.02.006

41. Quintas V, Prada-Lopez I, Donos N, Suarez-Quintanilla D, Tomas I (2015) In situ neutralisation of the antibacterial effect of $0.2 \%$ chlorhexidine on salivary microbiota: quantification of substantivity. Arch Oral Biol 60(8):1109-1116. https://doi.org/10.1016/j. archoralbio.2015.04.002

42. Olthof ED, Rentenaar RJ, Rijs AJ, Wanten GJ (2013) Absence of microbial adaptation to taurolidine in patients on home parenteral nutrition who develop catheter related bloodstream infections and use taurolidine locks. Clin Nutr 32(4):538-542. https://doi.org/10. 1016/j.clnu.2012.11.014

43. Hartel C, Scholz T, Kuhn M, Bendiks M, Gopel W, Lauten M, Herting E (2013) Innate immune responses to Stenotrophomonas maltophilia in immunocompromised pediatric patients and the effect of taurolidine. J Microbiol Immunol Infect 46(2):115-120. https://doi.org/10.1016/j.jmii.2012.04.002

44. Chromik AM, Muller AM, Albrecht M, Rottmann S, Otte JM, Herdegen T, Uhl W, Mittelkotter U (2007) Oral administration of taurolidine ameliorates chronic DSS colitis in mice. J Investig Surg 20(5):273-282. https://doi.org/10.1080/08941930701598784

45. Rohner E, Kolar P, Seeger JB, Arnholdt J, Thiele K, Perka C, Matziolis G (2011) Toxicity of antiseptics against chondrocytes: what is best for the cartilage in septic joint surgery? Int Orthop 35(11):1719-1723. https://doi.org/10.1007/s00264-010-1178-2

46. Ulusoy AT, Kalyoncuoglu E, Reis A, Cehreli ZC (2016) Antibacterial effect of $\mathrm{N}$-acetylcysteine and taurolidine on planktonic and biofilm forms of Enterococcus faecalis. Dent Traumatol 32(3):212-218. https://doi.org/10.1111/edt.12237

47. John G, Schwarz F, Becker J (2015) Taurolidine as an effective and biocompatible additive for plaque-removing techniques on implant surfaces. Clin Oral Investig 19(5):1069-1077. https://doi.org/10. 1007/s00784-014-1337-8

48. Umeda M, Takeuchi Y, Noguchi K, Huang Y, Koshy G, Ishikawa I (2004) Effects of nonsurgical periodontal therapy on the microbiota. Periodontol 2000(36):98-120. https://doi.org/10.1111/j.16000757.2004.03675.x

49. Bonito AJ, Lux L, Lohr KN (2005) Impact of local adjuncts to scaling and root planing in periodontal disease therapy: a systematic review. J Periodontol 76(8):1227-1236. https://doi.org/10.1902/ jop.2005.76.8.1227

50. Drisko CL (2014) Periodontal debridement: still the treatment of choice. J Evid Based Dent Pract 14(Suppl):33-41 e1. https://doi.org/10.1016/j.jebdp.2014.02.007 